\title{
Lingala Language
}

National Cancer Institute

\section{Source}

National Cancer Institute. Lingala Language. NCI Thesaurus. Code C154002.

A Niger-Congo Bantu language spoken throughout the northwestern part of the Democratic Republic of the Congo and a large part of the Republic of the Congo. 